\title{
Nanoparticulate magnetite thin films as electrode materials for the fabrication of electrochemical capacitors
}

\author{
Suh Cem Pang $\cdot$ Wai Hwa Khoh $\cdot$ Suk Fun Chin
}

Received: 10 December 2009/Accepted: 14 May 2010/Published online: 25 May 2010

(C) Springer Science+Business Media, LLC 2010

\begin{abstract}
Magnetite nanoparticles in stable colloidal suspension were prepared by the co-precipitation method. Nanoparticulate magnetite thin films on supporting stainless steel plates were prepared by drop-coating followed by heat treatment under controlled conditions. The effects of calcination temperature and atmosphere on the microstructure and electrochemical properties of nanoparticulate magnetite thin films were investigated. Nanoparticulate magnetite thin films prepared under optimized conditions exhibited a specific capacitance value of $82 \mathrm{~F} / \mathrm{g}$ in mild aqueous $1.0 \mathrm{M} \mathrm{Na}_{2} \mathrm{SO}_{4}$ solution. Due to their high charge capacity, good cycling reversibility, and stability in a mild aqueous electrolyte, nanoparticulate magnetite thin films appear to be promising electrode materials for the fabrication of electrochemical capacitors.
\end{abstract}

\section{Introduction}

The ever increasing miniaturization of portable electronic and communication devices such as laptop, cellular phones, and personal digital assistants (PDA) have led to increasing demands for energy-storage systems with high power capability and energy density, high reversibility, and long cycle life. Due to the low power capability of batteries and the low energy density of conventional capacitors, these charge storage systems are unable to meet the demands of modern devices, which require both high

S. C. Pang $(\bowtie) \cdot$ W. H. Khoh · S. F. Chin

Faculty of Resource Science and Technology, Department

of Chemistry, Universiti Malaysia Sarawak, 94300 Kota

Samarahan, Sarawak, Malaysia

e-mail: scpang@frst.unimas.my; suhcem@gmail.com power capability and high energy density. Electrochemical capacitors which possess high power capability and moderately high energy density are able to fill in the gap between batteries and conventional capacitors. In addition, the energy-storage mechanisms in electrochemical capacitors are simpler and highly reversible which ensure a very long cycle life of exceeding 100,000 cycles [1,2].

Recently, various types of transition metal oxides such as manganese oxides and ruthenium oxides have been investigated as electrode materials for the fabrication of electrochemical capacitors. Each of these materials possesses its own limitations and advantages [3, 4]. Nanoparticulate magnetite $\left(\mathrm{Fe}_{3} \mathrm{O}_{4}\right)$ thin film is another potential electrode material which has received considerable attention due to its superior electrochemical properties, environmental friendliness, and low cost. Wu et al. reported that magnetite crystallites electrocoagulated on conductive matrix exhibited specific capacitance values that varied over a large range between 30 and $500 \mathrm{~F} / \mathrm{g}$ in $1.0 \mathrm{M}$ $\mathrm{Na}_{2} \mathrm{SO}_{3}$ aqueous electrolytes [5, 6]. However, studies by $\mathrm{Wu}$ et al. focused only on the electrochemical properties of magnetite nanocrystallites without considering the effects of surface morphology and microstructure on their electrochemical properties. Elucidating the microstructureproperty relationship for the magnetite electrodes is crucial for enhancing their electrochemical properties by optimizing their surface morphological characteristics and microstructural parameters. In this study, we have focused on the characterization of nanoparticulate magnetite thin films prepared under various synthesis and post-synthesis conditions, and elucidating the effects of microstructure on their electrochemical properties. Besides, the potential utility of nanoparticulate magnetite thin films as electrode materials for the fabrication of electrochemical capacitors was evaluated. 